\title{
Estudo do potencial antimicrobiano e citotóxico da espécie Pouteria venosa (Sapotaceae)
}

\begin{abstract}
SANTOS, R.F.E.P.'; SILVA, I.S.M.2; VERÍSSIMO, R.C.S.S.1; LÚCIO, I.M.L.'; CAMPESATTO, E.A.'; CONSERVA, L.M.'; BASTOS, M.L.A. ${ }^{*}$

-Universidade Federal de Alagoas, Escola de Enfermagem e Farmácia. Campos A.C. Simões, Av. Lourival Melo Mota, s/n, Tabuleiro dos Martins, Maceió - AL, CEP: 57072-900; 'Universidade Tiradentes, Departamento de Biotecnologia. Av. Murilo Dantas, 54, Aracaju - SE, CEP: 49032-490. *Autor para correspondência: Iysetebastos@ gmail.com
\end{abstract}

\begin{abstract}
RESUMO: Estudo experimental in vitro que objetivou investigar o potencial antimicrobiano e citotóxico de quatro frações e um extrato etanólico da espécie Pouteria venosa usada como planta medicinal. A atividade antimicrobiana foi determinada pelos testes de sensibilidade microbiana, como o método de difusão em disco e o método da microdiluição em caldo, para a determinação da Concentração Inibitória Mínima (CIM). Obteve-se a avaliação da citotoxicidade por meio do método colorimétrico do Metiltetrazolium. No estudo da atividade antimicrobiana, os principais resultados foram obtidos contra Staphylococus aureus para a fração AcOEt das cascas do caule, CIM de $125 \mu \mathrm{g} / \mathrm{mL}$; Streptococcus pneumoniae e Proteus mirabilis para a fração AcOEt das cascas do caule, CIM de $250 \mu \mathrm{g} / \mathrm{mL}$; Staphylococus epidermidis, Pseudomonas aeruginosa para a fração AcOEt das folhas e cascas do caule, CIM de $250 \mu \mathrm{g} / \mathrm{mL}$. Todas as amostras foram inativas para os fungos testados. A fração AcOEt das cascas do caule foi considerada atóxica, podendo ser utilizada em testes pré-clínicos in vivo.
\end{abstract}

Palavras-chave: Plantas medicinais, Testes de sensibilidade microbiana, Viabilidade celular, Sapotaceae.

\begin{abstract}
Study of antimicrobial and cytotoxic potential of Pouteria venosa species (Sapotaceae). This experimental in vitro study aimed to investigate the antimicrobial and cytotoxic potential of four fractions and one ethanolic extract of the specie Pouteria venosa used as a medicinal plant. The antimicrobial activity was determined by microbial sensitivity tests, as the method of disk diffusion and the broth microdilution method for determination of Minimum Inhibitory Concentration (MIC). The evaluation of the cytotoxicity was obtained by the Metiltetrazolium colorimetric method. In the antimicrobial activity research, the main results were obtained against the Staphylococcus aureus for the AcOEt fraction of the stem bark MIC $125 \mathrm{\mu g} / \mathrm{mL}$, Streptococcus pneumoniae and Proteus mirabilis for the AcOEt fraction from the stem bark, CIM $250 \mu \mathrm{g} / \mathrm{mL}$, Staphylococcus epidermidis, Pseudomonas aeruginosa to the AcOEt fraction of the leaves and stem bark, MIC $250 \mu \mathrm{g} / \mathrm{mL}$. All samples did not react for the fungi tested. The AcOEt fraction of the stem bark was considered non-toxic and can be used at in vivo pre-clinical testing.
\end{abstract}

Keywords: Medicinal plants, Microbial sensitivity tests, Cell Viability, Sapotaceae.

\section{INTRODUÇÃO}

A utilização e a investigação de plantas medicinais no Brasil têm como aliados a grande diversidade vegetal e o baixo custo associado à terapêutica, o que vem despertando a atenção dos programas de assistência à saúde e profissionais (Santos et al., 2011). Cita-se a aprovação da Política Nacional de Práticas
Integrativas e Complementares (PNPIC) no Sistema Único de Saúde (SUS), pelo Ministério da Saúde, na qual se insere a fitoterapia, como parte essencial das políticas públicas de saúde, meio ambiente, desenvolvimento econômico e social (Brasil, 2006).

A literatura e o uso popular reportam 
à família Sapotaceae atividade antibacteriana, antifúngica, antiviral, antitumoral, anti-helmíntica, analgésica, antipirética e antinflamatória, estrogênica, antiespasmolítica, anticonvulsivante, depressora do SNC e anti-hiperglicêmica, dentre outras (Montenegro et al., 2006; Silva et al., 2009). Uma classe de substâncias muito comum nesta família são os triterpenos, para os quais algumas das atividades biológicas citadas estão relacionadas (Silva, 2007). A ocorrência de alcaloides, flavonoides, benzenoides, fenilpropanoides e naftoquinonas, também tem sido relatada em várias espécies de Sapotaceae (Hussain et al., 2007).

Condessa (2011) evidenciou algumas espécies do gênero Pouteria (Sapotaceae), as quais apresentam atividades biológicas relevantes, como a $P$. caimito e $P$. ramiflora, usadas popularmente, uma como antimicrobiano e antimalárico, com atividade antioxidante e fotoprotetora contra raios UVA e UVB comprovada, e a outra no tratamento de verminoses, disenteria, dor e inflamação, possuindo comprovação científica de atividade antinociceptiva, antinflamatória, antioxidante, fotoprotetora, inibitória da alfa-amilase e antimicrobiana, respectivamente. Enquanto a $P$. torta é usada, popularmente, como antidiarreico e com comprovação científica de atividade antimicrobiana e antifúngica.

A Pouteria venosa é uma árvore de médio porte, medindo de 8 a 20 metros de altura, sendo abundante em áreas da Mata Atlântica (Lorenzi, 2009). De acordo com Montenegro et al (2006), extratos oriundos das folhas $\left(\mathrm{CHCl}_{3}\right)$, cascas do caule $\left(\mathrm{CH}_{2} \mathrm{Cl}_{2}\right)$ e caule $\left(\mathrm{C}_{6} \mathrm{H}_{14}\right.$-AcOEt 1:1) apresentaram atividade antioxidante e foram ativos contra larvas do Aedes aegypti, além do isolamento de cinco substâncias inéditas para a espécie (taraxerol; ácido

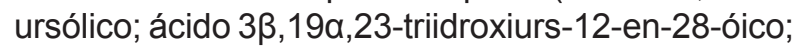
ácido $2 \alpha, 3 \alpha, 19 \alpha, 23$-tetraidroxiurs-12-en-28-óico e espinasterol).

O estudo da $P$. venosa, se justifica pela incorporação de novos conhecimentos, considerando que a espécie apresenta alta probabilidade de atividade antimicrobiana, que ainda não foi explorada, visto que esta atividade foi relatada para algumas espécies de sua família e gênero e seus constituintes. Portanto, neste estudo, objetivou-se investigar o potencial antimicrobiano e citotóxico de $P$. venosa.

\section{MATERIAL E MÉTODO}

\section{Obtenção do material vegetal}

A Pouteria venosa (Mart.)Baehni conhecida como "tuturubá, leiteiro, Bapeba, Sapota preta" foi coletada durante a primavera, na área de preservação ambiental Santa Rita (09³7'30" S e $35^{\circ} 49^{\prime} 00^{\prime \prime} \mathrm{W}$ ) e sua exsicata encontra-se depositada no Herbário do Instituto do Meio Ambiente de Alagoas, com a identificação MAC n 23.816.

$\mathrm{O}$ extrato em EtOH do caule e as frações em AcOEt e $\mathrm{MeOH} / \mathrm{H}_{2} \mathrm{O}$ das folhas e cascas do caule da $P$. venosa foram fornecidos pelo Laboratório de Pesquisa em Química dos Produtos Naturais/ LPQPN do Instituto de Química e Biotecnologia/ UFAL para avaliação do potencial antimicrobiano e citotóxico.

O material vegetal das folhas, casca do caule e caule, após secagem à temperatura ambiente e trituração, foi individualmente extraído, através de maceração com EtOH a 90\%. Após a concentração das soluções em evaporador rotativo e secagem à temperatura ambiente, obteve-se o extrato bruto.

Os extratos em EtOH das folhas e cascas do caule foram suspensos em solução $\mathrm{MeOH}-\mathrm{H}_{2} \mathrm{O}$ (3:2) e extraídos sucessivamente em $\mathrm{C}_{6} \mathrm{H}_{14}, \mathrm{CHCl}_{3}$ e AcOEt. Novamente as soluções foram concentradas em evaporador rotativo e secas à temperatura ambiente, obtendo-se as respectivas frações.

\section{Microrganismos}

As linhagens microbianas utilizadas neste estudo foram padronizadas pela American Type Cell Cellection - ATCC/Manassas - VA/USA, sendo as bactérias Gram-positivas: Staphylococcus aureus (25923), Staphylococcus epidermides (14990), Streptococcus pneumoniae (49619); Gramnegativas: Pseudomonas aeruginosa (27853), Escherichia coli (14942), Klebsiella pneumoniae (10031), Shigella flexneri (12022), Proteus mirabilis (14153), Acinetobacter calcoaceticus (19606), Salmonella entérica (13311), Enterobacter aerogenes (13048), Enterobacter cloacae (13047) e os fungos: Candida albicans (10231), Saccharomyces cerevisiae (18824) e Aspergillus brasiliensis (16404).

\section{Ensaios antimicrobianos}

No teste de difusão em disco, $100 \mathrm{mg}$ das frações de AcOEt e $\mathrm{MeOH} / \mathrm{H}_{2} \mathrm{O}$ das folhas, cascas do caule e do extrato $\mathrm{EtOH}$ do caule foram solubilizados em EtOH, obtendo-se soluções estoques na concentração $2.000 \mu \mathrm{g} / \mathrm{mL}$. No teste de determinação da CIM, 2 mg das frações e do extrato EtOH foram solubilizados em DMSO a $10 \%$, obtendo-se a mesma concentração estoque de $2.000 \mu \mathrm{g} / \mathrm{mL}$ (CLSI, 2012). Para a avaliação da atividade antibacteriana e antifúngica, inóculos bacterianos e fúngicos foram preparados de acordo com protocolo (CLSI, 2012).

Discos estéreis de papel Whatman $\mathrm{n}^{\circ} 1$, de $6 \mathrm{~mm}$ de diâmetro, foram impregnados com $20 \mu \mathrm{L}$ das soluções estoques e, depois de secos, foram pressionados contra a superfície do meio de cultivo com o inóculo. Posteriormente, estas placas 
foram acondicionadas em estufa bacteriológica por 24 horas a $35^{\circ} \mathrm{C}$, no caso das bactérias, e a $28^{\circ} \mathrm{C}$ por 48 horas, dos fungos (Bastos et al., 2009). Foi avaliada a presença ou ausência do halo de inibição (Ayres et al., 2008).

O controle positivo da viabilidade bacteriana foi escolhido a partir do teste de sensibilidade antimicrobiana (Ayres et al., 2008). Para as bactérias Gram-positivas, foi usado Ceftriaxona (30 $\mu \mathrm{g} /$ disco) e para as Gram-negativas Ciprofloxacina (5 $\mu \mathrm{g} /$ disco). Para os fungos Candida albicans e Saccharomyces cerevisiae, foi usado o Miconazol (50 $\mathrm{\mu g} /$ disco) e para Aspergillus brasiliensis o Tioconazol (50 $\mu \mathrm{g} / \mathrm{disco})$. Como controle negativo, utilizou-se o EtOH a $90 \%$.

Para determinação da CIM, o inóculo de $1,5 \times 10^{8}$ UFC/mL foi rediluído numa proporção de 1:10 (v/v) para obter a concentração padrão utilizada (104 UFC/ mL). A CIM, conforme descrita por Manetti et al. (2010), foi realizada em microplacas de poliestireno estéreis de 96 poços. Um volume de $200 \mu \mathrm{L}$ das soluções estoques foi inoculado, em triplicata, na linha A. Os demais orifícios foram preenchidos com $100 \mu \mathrm{L}$ de caldo $\mathrm{BHI}$ duplamente concentrado (Bordignon-Junior et al., 2012).

Em seguida, uma alíquota de $100 \mu \mathrm{L}$ do conteúdo da linha A foi transferido para a linha $B$ e, após homogeneização, transferido para a linha $\mathrm{C}$, repetindo-se este procedimento até a linha $\mathrm{H}$. Obtendo-se as concentrações em $\mu \mathrm{g} / \mathrm{mL}$ de 1.000; 500; 250; 125; 62,5; 31,25 e 15,62. Posteriormente, em cada orifício, foi adicionado $5 \mu \mathrm{L}$ de inóculo microbiano. Para o controle positivo da viabilidade bacteriana, utilizou-se o caldo $\mathrm{BHI}$ e o inóculo microbiano (5 $\mu \mathrm{L})$; como controle negativo, utilizouse o DMSO a 10\%; e para o controle de esterilidade, apenas o caldo (Almeida et al., 2012).

As placas foram incubadas em estufa a 35 ${ }^{\circ} \mathrm{C}$ por 18 horas, para as bactérias, e $28^{\circ} \mathrm{C}$ por 36 horas, para os fungos. Após este período, foram adicionados $20 \mu \mathrm{L}$ de TTC a $5 \%$ (v/v) em cada poço, e as placas foram reincubadas por 2 horas. A mudança de incolor para coloração vermelha significou a presença de microrganismos. O grau de atividade foi determinado segundo os seguintes critérios: CIM $\leq 100 \mu \mathrm{g} / \mathrm{mL}$ (ativa); CMI >100 e $\leq 500$ $\mu \mathrm{g} / \mathrm{mL}$ (moderadamente ativa); CMI > $500 \leq 1000 \mu \mathrm{g} /$ $\mathrm{mL}$ (baixa atividade); e CIM > $1000 \mu \mathrm{g} / \mathrm{mL}$ (inativos) (Ayres et al., 2008).

\section{Ensaio da citotoxicidade}

Para este ensaio, foi utilizado o método colorimétrico do MTT, baseado na atividade mitocondrial das células pela da redução do MTT, por meio da clivagem do sal de tetrazólio. A densidade óptica resultante do teste MTT foi determinada por espectrofotômetro. Foram utilizados macrófagos da linhagem J774, na densidade de $2 \times 10^{5}$ células por poço, cultivados em meio DMEM e suplementado com $10 \%$ de soro fetal bovino, semeadas em placas de 96 poços (Valadares et al., 2007).

Os resultados foram analisados no programa Graphpad prism $5.0 \circledast$, submetidos ao teste T de Student e os dados expressos em gráfico. Os valores foram considerados significativos quando $p<0,05$.

\section{RESULTADO E DISCUSSÃO}

As frações e o extrato em EtOH demonstraram atividade antimicrobiana em oito dos quinze microrganismos avaliados no teste de difusão em disco. Três delas Gram-positivas: S. aureus, $S$. epidermides, $S$. pneumoniae, e cinco Gramnegativas: $P$. aeruginosa, $S$. flexneri, $P$. mirabilis, $A$. calcoaceticus e E. aerogenes (Tabela 01).

As frações AcOEt das folhas e das cascas do caule apresentaram um potencial antimicrobiano promissor, com atividade antibacteriana (halos de inibição $\geq 17 \mathrm{~mm}$ ) frente as linhagens de $S$. aureus, $S$. epidermidis e S. pneumoniae. Sendo ativas também diante da linhagem de $P$. aeruginosa, com

TABELA 1. Atividade antibacteriana das frações e do extrato bruto da Pouteria venosa.

\begin{tabular}{|c|c|c|c|c|c|c|c|}
\hline \multirow{4}{*}{ Microrganismo } & \multicolumn{6}{|c|}{ Média dos halos de inibição* (mm) } & \multirow{4}{*}{$\mathrm{C}-$} \\
\hline & Folhas & Folhas & Cascas do & Cascas do & Caule & & \\
\hline & Fr. AcOEt & Fr. $\mathrm{MeOH} / \mathrm{H}_{2} \mathrm{O}$ & Caule & Caule Fr. & Ext. bruto & $\mathrm{C}+$ & \\
\hline & & & Fr. AcOEt & $\mathrm{MeOH} / \mathrm{H}_{2} \mathrm{O}$ & $\mathrm{EtOH}$ & & \\
\hline S. aureus & 14,4 & 8,5 & 19,0 & 8,0 & 7,0 & 26,0 & - \\
\hline S. epidermides & 17,7 & 10,7 & 21,4 & - & 8,0 & 34,0 & - \\
\hline P. aeruginosa & 12,0 & 8,5 & 11,0 & - & 7,0 & 32,0 & - \\
\hline S. pneumoniae & 22,0 & 11,7 & 19,5 & - & - & 35,0 & - \\
\hline P. mirabilis & 9,0 & 8,4 & 10,4 & - & - & 37,9 & - \\
\hline S. flexneri & 9,0 & - & 10,0 & - & - & 42,5 & - \\
\hline A. calcoaceticus & 8,4 & - & 8,0 & - & 7,0 & 28,9 & - \\
\hline E. aerogenes & 10,0 & - & 10,0 & - & - & 40,0 & - \\
\hline
\end{tabular}

\footnotetext{
* média da triplicata; $\mathrm{C}+=$ controle positivo; $\mathrm{C}$ - = controle negativo.
} 
halo de inibição entre 9 e 14 mm (Figura 01A).

Os resultados obtidos com determinação da CIM demonstraram que a fração AcOEt das cascas do caule foi considerada a fração de melhor potencial antimicrobiano, com atividade moderada para sete das oito bactérias avaliadas e uma CIM de $125 \mu \mathrm{g} /$ $\mathrm{mL}$ para $\mathrm{S}$. aureus (Figura $01 \mathrm{~B}$ ), apresentando-se inativa apenas para $E$. aerogenes (Tabela 02). Estes dados corroboram os de uma pesquisa realizada com os extratos hexânicos e etanólicos das folhas de Pouteria torta, os quais apresentaram ação antimicrobiana contra $S$. aureus e $P$. aeruginosa (Lopez, 2005).

Em outros estudos utilizando as folhas, flores e raízes da $P$. pallida e folhas da $P$. gardnerii, observou-se que também ocorreu a inibição do crescimento de $S$. aureus. No entanto, a segunda espécie foi igualmente testada contra $P$. aeruginosa e não foi ativa para este microrganismo, contrariando os dados do presente estudo (Humason, 2005; Silva, 2007).

Estudo realizado por Kothari \& Seshadri (2010) revelou que as linhagens de S. flexneri, S. paratyphi, V. cholerae e S. epidermidis revelaramse sensíveis a um ou mais dos extratos da espécie Manilkara zapota (Sapotaceae). O extrato metanólico dos frutos da Mimusops elengi (Sapotaceae) apresentou atividade contra S. typhi (Patel \& Rao, 2012). Em outro estudo, a Manilkara hexandra (Sapotaceae) foi ativa contra $S$. epidermidis e $S$. aureus. Estes dados, quando comparados com o presente estudo, reforçam a evidência de atividade antimicrobiana em espécies da família Sapotaceae (Mahida \& Mohan, 2007).

Ruela et al. (2011) observou que a fração AcOEt das cascas do caule de Bumelia sartorum Mart.(Sapotaceae) foi ativa contra $S$. aureus com uma CIM que variou de 256 a $512 \mu \mathrm{g} / \mathrm{mL}$. O
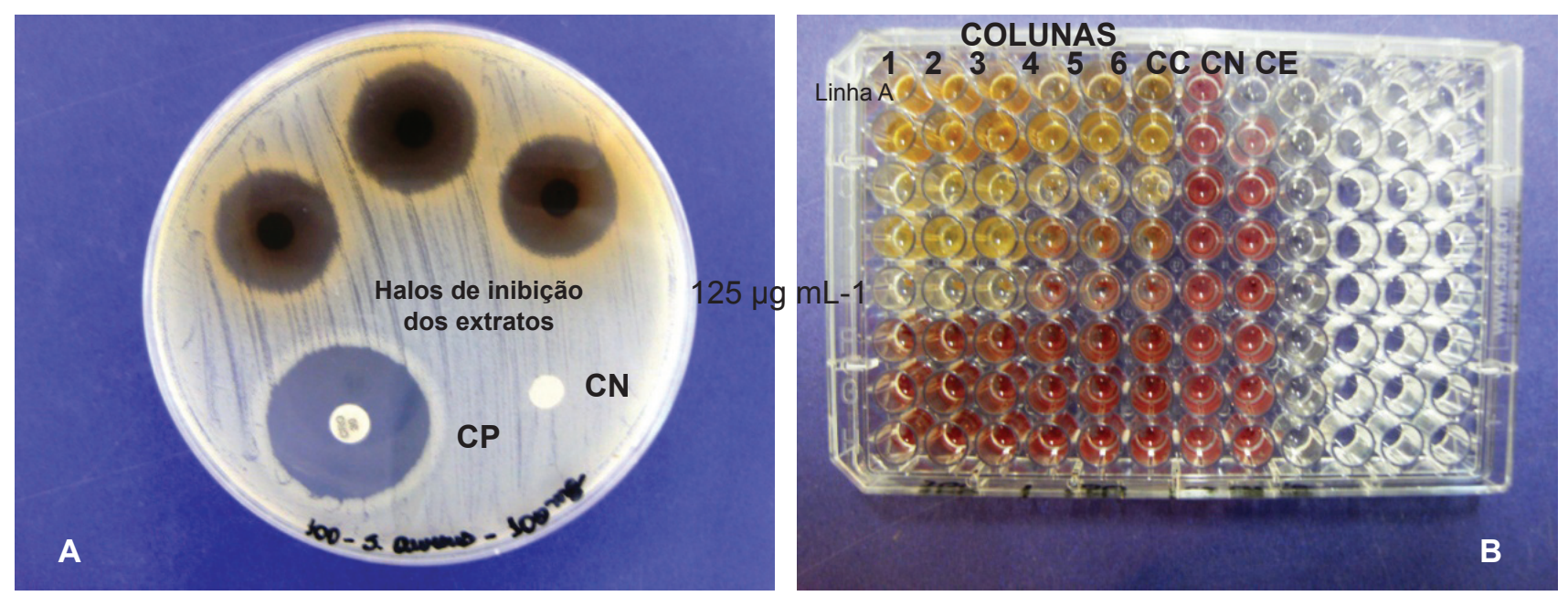

FIGURA 1- A. Halos de inibição da fração AcOEt.; CP - Controle Positivo; CN - Controle Negativo. B. Os números de 1 a 3 representam a triplicata da fração AcOEt e a sensibilidade da linhagem de $S$. aureus até a concentração de $125 \mu \mathrm{g} / \mathrm{mL}$; os números de 4 a 6 representam a fração $\mathrm{MeOH} / \mathrm{H}_{2} \mathrm{O}$ e a sensibilidade da linhagem de S. aureus até a concentração de $500 \mu \mathrm{g} / \mathrm{mL}$; CC - Controle de Crescimento; CN - Controle Negativo; CE Controle de Esterilidade.

TABELA 2. Concentração Inibitória Mínima (CIM) das frações e extrato EtOH da espécie Pouteria venosa frente aos microrganismos testados.

\begin{tabular}{lccccc}
\hline \multirow{2}{*}{ Microrganismo } & \multicolumn{5}{c}{ Concentração Inibitória Mínima - CIM $(\boldsymbol{\mu g} / \mathbf{m L})^{*}$} \\
\cline { 2 - 6 } & $\begin{array}{c}\text { Folhas } \\
\text { Fr. AcOEt }\end{array}$ & $\begin{array}{c}\text { Folhas } \\
\text { Fr. MeOH/ } \mathrm{H}_{2} \mathrm{O}\end{array}$ & $\begin{array}{c}\text { Cascas do Caule Fr. } \\
\text { MeOH/ } / \mathrm{H}_{2} \mathrm{O}\end{array}$ & $\begin{array}{c}\text { Cascas do Caule } \\
\text { Fr. AcOEt }\end{array}$ & $\begin{array}{c}\text { Caule } \\
\text { Ext. bruto EtOH }\end{array}$ \\
\hline S. aureus & 250 & 500 & 500 & 125 & 500 \\
S. epidermidis & 250 & 1000 & 1000 & 250 & 1000 \\
P. aeruginosa & 250 & 500 & 1000 & 250 & 1000 \\
S. pneumoniae & 500 & 500 & 1000 & 250 & 1000 \\
P. mirabilis & 500 & 1000 & 1000 & 250 & 1000 \\
S. flexneri & 1000 & 1000 & $>1000$ & 500 & 1000 \\
A. calcoaceticus & 500 & 500 & 1000 & 500 & 1000 \\
E. aerogenes & 1000 & $>1000$ & $>1000$ & 1000 & $>1000$
\end{tabular}

*Interpretação da atividade inibitória: $\mathrm{CIM} \leq 100 \mu \mathrm{g} / \mathrm{mL}$ (ativa); CMI > 100 e $\leq 500 \mu \mathrm{g} / \mathrm{mL}$ (moderadamente ativa); CMI > 500 e $\leq 1000 \mu \mathrm{g} /$ $\mathrm{mL}$ (baixa atividade); e CIM $>1000 \mu \mathrm{g} / \mathrm{mL}$ (inativos e resistentes). 
estudo químico desta fração revelou abundância de compostos polifenólicos. Ainda, de acordo com o referido autor, esta atividade bactericida elege a referida fração como útil para o desenvolvimento de novos agentes antibacterianos contra infecções por S. aureus. Estes dados comparados com a Tabela 2 confirmam que a fração em AcOEt das cascas da $P$. venosa apresenta atividade contra $S$. aureus com uma CIM de $125 \mu \mathrm{g} / \mathrm{mL}$ revelando que tem maior poder bactericida que a $B$. sartorum.

O presente estudo também revelou que as frações da $P$. venosa em AcOEt das cascas do caule apresentaram atividade contra mais duas bactérias Gram positivas, S. epidermidis e S. pneumoniae e das folhas contra $S$. epidermidis, com CIM $=250$ $\mu \mathrm{g} / \mathrm{mL}$ (Tabela 2 ), sendo descrito pela primeira vez na literatura.

Das nove bactérias Gram negativas testadas, cinco apresentaram alguma sensibilidade frente ao extrato bruto e as frações da $P$. venosa. Entretanto, as frações em AcOEt se destacaram por apresentarem uma maior atividade contra $P$. aeruginosa (cascas do caule e folhas) e $P$. mirabilis

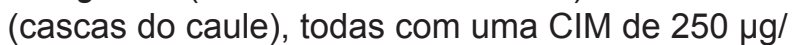
$\mathrm{mL}$ (Tabela 2). Em estudo realizado por Patel \& Rao (2012), o extrato em metanol da Mimusops elengi (Sapotaceae) exibiu atividade contra a cepa Gram negativa S. typhi com uma CIM de $1000 \mu \mathrm{g} /$ $\mathrm{mL}$. Este relato, quando confrontado com os dados do presente estudo, revela que a $P$. venosa é promissora contra cepas Gram negativas.

A ausência ou redução da ação bactericida em amostras vegetais frente às bactérias Gramnegativas tem sido relatada por pesquisadores, que afirmam ser esta característica uma peculiaridade da composição dos extratos, agindo sobre o sítio de ação dos microrganismos, ou seja, estão relacionados, principalmente, com a desintegração da membrana citoplasmática. Este fator torna os microrganismos Gram negativos mais resistentes (Silva \& Fernandes Junior, 2010; Ruela et al., 2011).

Os fungos testados nesta pesquisa não foram sensíveis às amostras da Pouteria venosa, contrariando resultados de pesquisas anteriores, em que espécies do gênero Pouteria e/ou família Sapotaceae apresentaram atividade antifúngica, como o extrato metanólico e as frações a partir das cascas do caule de Tridesmostemon omphalocarpoides ativas contra espécies do gênero Candida(Kuete et al., 2006).

Da mesma forma, os extratos hexânicos e etanólicos das folhas de Pouteria torta ativos contra C. sphaerospermum (Alves, et al., 2000). A pouterina, obtida a partir de sementes de Pouteria torta, ativa contra F. oxysporum, C. lindemuthianum e S. cerevisiae (Boleti et al., 2007), o licor da madeira de $P$. ramiflora ativo contra $A$. niger e Trichoderma sp. (Costa et al., 2003); os extratos hidroetanólicos das folhas de $P$. psamophila e $P$. grandiflora ativas contra C. cladosporioides e C. sphaerospermum, respectivamente, porém inativos frente à $C$. albicans (Agripino et al., 2004).

Quanto ao teste de citotoxicidade, que avaliou a viabilidade celular da fração AcOEt das cascas do caule, a concentração de $2000 \mu \mathrm{g} / \mathrm{mL}$ induziu alta toxicidade, enquanto a concentração de $1000 \mu \mathrm{g} / \mathrm{mL}$ induziu baixa toxicidade. No entanto, na concentração de $200 \mu \mathrm{g} / \mathrm{mL}$ não houve toxicidade estatisticamente significativa (Figura 02).

Para Freshney (2000), a toxicidade é um

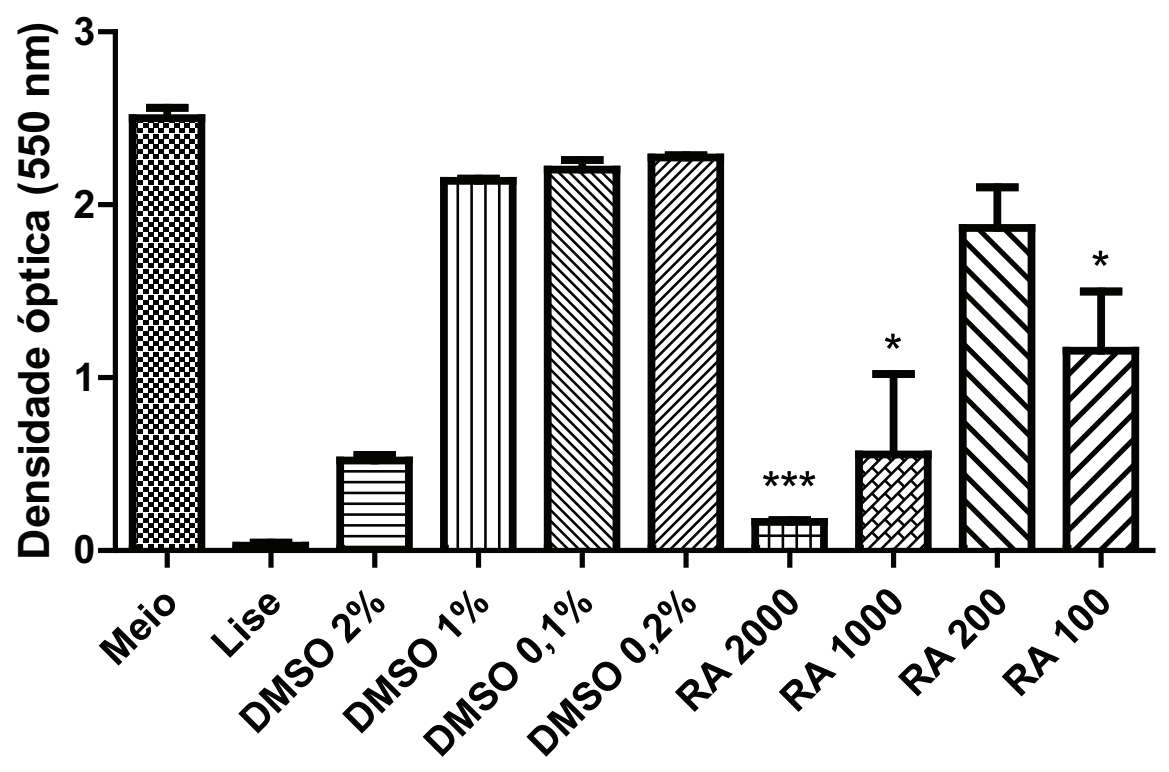

FIGURA 2. Efeitos da fração AcOEt da casca do caule (RA) nas concentrações $2.000,1.000,200$ e $100 \mu \mathrm{g} / \mathrm{mL}$. ${ }^{*}(P<0,05),{ }^{* *}(P<0,01) e^{* * *}(P<0,001)$. 
fator que limita a liberação e consumo de fármacos. Assim, comparando-se a viabilidade celular do meio de cultura, que é de $100 \%$, com a fração AcOEt na concentração de $2000 \mu \mathrm{g} / \mathrm{mL}$, evidenciou-se uma viabilidade celular de $6,98 \%$, na concentração de $1000 \mu \mathrm{g} / \mathrm{mL}$, obteve-se $55,26 \%$ e, na de $200 \mu \mathrm{g} /$ $\mathrm{mL}$, foi de $84,50 \%$. Essa relação comprova que o mais sensato é utilizar a concentração de $200 \mu \mathrm{g} /$ $\mathrm{mL}$, pela fração se comportar de forma equitativa, promovendo a viabilidade celular e não induzindo toxicidade celular nos macrófagos.

Segundo Castro et al. (2004), os macrófagos utilizados pelo método colorimétrico do Metiltetrazolium após contato com um agente agressor, liberam citocinas e mediadores pró-inflamatórios que iniciam e amplificam o processo inflamatório, participando da resposta do organismo frente a qualquer estímulo agressor físico, químico ou bacteriano. Por isso, as alterações morfológicas e funcionais destes podem ser avaliadas in vitro.

Diante disso, é seguro afirmar que, se um material induz uma reação citotóxica em testes envolvendo culturas de células, é muito provável que apresente toxicidade no teste in vivo. Sendo assim, diante da diversidade do comportamento da fração testada frente às diferentes concentrações utilizadas, afirma-se que o mais sensato é utilizar a

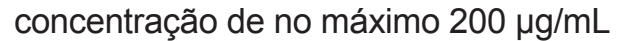

\section{CONCLUSÃO}

A avaliação da atividade antimicrobiana evidenciou o potencial antibacteriano das frações em AcOEt das folhas e das cascas do caule da espécie Pouteria venosa, demonstrando atividade frente as linhagens de bactérias Gram-positivas ( $S$. aureus, $S$. epidermidis e S. pneumoniae) e Gram-negativas ( $P$. aeruginosa e $P$. mirabilis). Com destaque para a fração AcOEt das cascas do caule que atende de forma satisfatória aos requisitos de ser ativa contra $S$. aureus e apresenta viabilidade celular, promissora no percurso dos ensaios pré-clínicos in vivo.

\section{REFERÊNCIA}

AGRIPINO, D.G. et al. Screening of Brazilian Plant for antimicrobial and DNA-Dmamging Activities. Atlantic rain forest-ecological station Jureia-Itains. Biota Neotropica, v.4, n.2, p.1-15, 2004.

ALMEIDA, L.C.T. et al. Potencial antimicrobiano do óleo de coco no tratamento de feridas. Revista da Rede de Enfermagem do Nordeste, v.13, n.4, p.880-87, 2012.

ALVES, T.M.A. et al. Biological screening of Brazilian medicinal plants. Memórias do Instituto Oswaldo Cruz, v.95, n.3, p.367-73, 2000.

AYRES, M.C.C. et al. Atividade antibacteriana de plantas uteis e constituintes químicos da raiz de Copernicia prunifera. Revista Brasileira de Farmacognosia, v.18, n.1, p.90-97, 2008.

BASTOS, M.L.A. et al. Studies on the antimicrobial activity and brine shrimp toxicity of Zeyheria tuberculosa (Vell.) Bur. (Bignoniaceae) extracts and their main constituents. Annals of Clinical Microbiology and Antimicrobials, v.8, n.16, p.1-6, 2009.

BOLETI, A.P. et al. Insecticidal and antifugal activity of a protein from Pouteria torta seeds with lectinlike properties. Journal of Agriculturral and Food Chemistry, v.55, n.7, p.2653-58, 2007.

BORDIGNON-JUNIOR, S.E. et al. Inibição do crescimento de bactérias Gram-negativas em microdiluição por tratamento com Nisina e EDTA. Journal of Biotechnology and Biodiversity, v.3, n. 4, p.127-35, 2012.

BRASIL - Ministério da Saúde. A fitoterapia no SUS e o Programa de Pesquisa de Plantas Medicinais da Central de Medicamentos. Brasília: Ministério da Saúde, 2006.

CASTRO, C.M.M.B. et al. Citotoxicidade de biopolímero de cana-de-açúcar. Revista Anais da Faculdade de Medicina da Universidade Federal de Pernambuco, v.49, n.2, p.119-23, 2004.

CLSI - Clinical and Laboratory Standards Institute. Performance Standards for Antimicrobial Disk Susceptibility Tests. Document M02-A11. Approved Standard - 11.ed. Wayne. PA: Clinical and Laboratory Standards Institute, 2012.

CONDESSA, M.B. Avaliação da atividade antioxidante e alelopática de plantas medicinais. Faculdade de ciências e saúde. 2011. 101p. Dissertação (Mestrado em Ciências da Saúde) - Programa de Pós-Graduação em Ciências da Saúde. Universidade de Brasília, Brasília.

COSTA, A.F. et al. Estudo comparativo entre produtos químicos preservantes e licores pirolenhosos na inibição de fungos emboloradores. Revista Brasil Florestal, v.21, n. 75, p.24-30, 2003.

FRESHNEY R.I. Culture of animal cells: a manual of basic technique. 4.ed. New York: Wiley-Blackwell, 2000. 608p.

HUMASON, A.W. A search for multi-drug resistance pump inhibitor molecules by isolation of natural products. 2005. 75 p. Dissertation (Master's Degree Graduate With a Major in Chemistry) - Faculty of Dedman College, Southern Methodist University, Texas.

HUSSAIN, H. et al. Lapachol: An overview. Department of Chemistry, University of Paderborn, Paderborn, Germany. Archive for Organic Chemistry, v.2, p.14571, 2007.

KOTHARI, V.; SESHADRI, S. In vitro antibacterial activity in seed extracts of Manilkara zapota, Anona squamosa and Tamarindus indica. Biological Research, v.43, n.2, p.165-68, 2010.

KUETE, V. et al. Antimicrobial activity of the methanolic extract from the stem bark of Tridesmostemon omphalocarpoides (Sapotaceae). Journal of Ethnopharmacology, v.104, n.1-2, p.5-11, 2006.

LORENZI, H. Árvores Brasileiras. 3. ed.. Nova Odessa (SP): Editora Plantarum, 2009. 384p.

LOPEZ, K.S.E. Estudo químico e atividade biológica de Pouteria torta (Mart.) Raldk (Sapotaceae). 2005. 197p. Dissertação (Mestrado em Ciências da Saúde) 
- Faculdade de Ciências da Saúde. Universidade de Brasília, Brasília.

MAHIDA, Y. \& MOHAN, J.S.S. Screening of plants for their potential antibacterial activity against Staphylococcus and Salmonella spp. Natural Product Radiance. v.6, n.4, p.301-05, 2007.

MANETTI, L.M. et al. Avaliação das atividades antimicrobiana, citotóxica, moluscicida e antioxidante de Bromelia antiacantha Bertol. (Bromeliaceae). Revista Brasileira de Plantas Medicinais, v.12, n.4, p.406-13, 2010.

MONTENEGRO, L.H.M. et al. Terpenóides e avaliação do potencial antimalárico, larvicida, anti-radicalar e anticolinesterásico de Pouteria venosa (Sapotaceae). Revista Brasileira de Farmacognosia, v.16(supl.), p.611-17, 2006.

PATEL, P.R.; RAO, T.V.R. Screening of antibacterial activity of some underutilized fruits of Sapotaceae. International Food Research Journal, v. 19 n. 3 p.1227-31, 2012.

SANTOS, R.L. et al. Análise sobre a fitoterapia como prática integrativa no Sistema Único de Saúde. Revista Brasileira de Plantas Medicinais, v.13, n.4, p.486-91,
2011.

SILVA, C.A.M. Contribuição ao estudo químico e biológico de Pouteria gardnerii (Mart. \& Miq.) Baehni (Sapotaceae). 2007. 197p. Dissertação (Mestrado em Ciências da Saúde) - Faculdade de ciências da saúde. Universidade de Brasília, Brasília.

SILVA, C.A.M. et al. Genus Pouteria: Chemistry and biological activity. Brazilian Journal of Pharmacognsosy, v.19, n.2A, p.501-09, 2009.

SILVA, N.C.C.; FERNANDES JUNIOR, A. Biological properties of medicinal plants: a review of their antimicrobial activity. Journal of Venomous Animals and Toxins including Tropical Diseases. v.16, n.3, p. 402-13, 2010.

RUELA, H.S. et al. Antibacterial and antioxidant activities and acute toxicity of Bumelia sartorum Mart., Sapotaceae, a Brazilian medicinal plant. Brazilian Journal of Pharmacognsosy, v. 21, n.1, p.86-91, 2011.

VALADARES, M.C. et al. Synadenium umbellatum: citotoxicidade e danos ao DNA de células da medula óssea de camundongos. Revista Brasileira de Ciências Farmacêuticas, v. 43, n. 4, p. 631-38, 2007. 